\title{
Specific word transfer as a measure of processing in the word-superiority paradigm
}

\author{
C. A. GORDON HAYMAN \\ University of Toronto, Toronto, Ontario, Canada \\ and \\ LARRY L. JACOBY
McMaster University, Hamilton, Ontario, Canada
}

\begin{abstract}
Explanations of context effects in the Reicher-Wheeler task and the letter-identification task appeal to word-based processing, yet these tasks provide no explicit measure of word processing. An experiment is reported which was designed to investigate the use of transfer in the wordidentification task as a measure of word-based processing in letter-identification tasks. It was found that encoding manipulations that determined whether a word-superiority effect was or was not found in a letter-identification task (e.g., Thompson \& Massaro, 1973) also determined whether transfer was or was not found in a subsequent word-identification task. The results of the experiment are discussed in terms of the utility of using transfer experiments as converging evidence about the presence and/or absence of processes that cannot be directly measured in other experimental paradigms.
\end{abstract}

Experimental investigations have demonstrated that a letter in a word is processed differently than a letter by itself (Estes, 1975; Reicher, 1969; Wheeler, 1970). In these studies, the presence of a word context facilitated the detection of constituent letters. Recent accounts of this effect have invoked processing that is based on specific and known words (McClelland \& Rumelhart, 1981; Paap, Newsome, McDonald, \& Schvaneveldt, 1982; Rumelhart \& McClelland, 1982). However, because these studies did not include an independent measure of word processing, the evidence for operations associated with specific words is indirect. The purpose of the present research was to provide such an independent measure. To do so, we used performance in the word-identification task (see Jacoby \& Dallas, 1981) as an index of word processing in a prior letter-identification task. To the extent that transfer from the letter-identification task to the wordidentification task can be shown to be limited to those conditions in which there is a word advantage in letter identification, such differential transfer provides converging evidence that processing associated with specific words mediates the perception of a letter in a word.

The sensitivity of the word-identification task makes it a good candidate as a measure of word processing (e.g., Morton, 1979). In this task, subjects are required to name words presented in a degraded fashion, and performance is measured in terms of the proportion of words correctly

Preparation of this article was supported by an NSERC grant to the second author. We thank Carol A. Macdonald for comments on earlier versions of this paper, and Ann Hollingshead for general assistance. Requests for reprints may be sent to Gordon Hayman, Department of Psychology, University of Toronto, Toronto, Ontario MSS IAl, Canada. identified. Of importance for the present purposes is the fact that it has been found that a single, prior presentation of a word increases the probability of that word's being identified in the word-identification task (Jacoby \& Dallas, 1981; Morton, 1979). This facilitation is modality specific and is not observed for visually similar words (Murrell \& Morton, 1974). That is, the facilitation observed from a prior presentation in the word-identification task occurs, in part, at the level of pattern-analyzing operations that are specific to individual words (Kolers, 1979; Kolers \& Roediger, 1984).

In the letter-identification task, sometimes referred to as the Reicher-Wheeler task, a target consisting of a string of letters or a single letter is flashed tachistoscopically and followed by an unrelated visual pattern mask. Sometimes the target is an English word, other times it is not. Shortly after the presentation of the target and the mask, the subject is tested by the presentation of a two-alternative forced-choice stimulus using two letters. One of these alternatives is correct in that it corresponds to the target stimulus. The subject's task is to indicate which of the alternatives was presented as the target. A primary conclusion of research using this task has been that letters are identified more accurately when embedded in a word than when seen as single letters (e.g., Estes, 1975; Reicher, 1969; Wheeler, 1970).

However, the status of words in mediating the letter advantage is uncertain, since a similar advantage over single letters is also found with pseudowords (letter strings that are similar to English words in orthographic structure; see McClelland \& Rumelhart, 1981, Paap et al., 1982, and Rumelhart \& McClelland, 1982, for a more extensive review). Furthermore, factors such as word fre- 
quency, which is highly predictive of word identification (Morton, 1979), are largely irrelevant in letter identification (Paap et al., 1982). These two findings have been interpreted as evidence for an orthographic encoding system that contains abstract rules for predicting the probability of sequential letter combinations (Massaro, Venezky, \& Taylor, 1979). In contrast, alternate explanations of letter context effects, such as those proposed by McClelland and Rumelhart (1981) and Paap et al. (1982), attribute the benefits provided by letter context to word-based constraints activated at the time of letter encoding. Although none of the theories speak to the issue of whether there should be a consequence of such word-based processing on subsequent word processing, it follows that if words presented during the letteridentification task facilitate subsequent processing of those words, some processing at the word level must have occurred in the letter-identification task.

However, simply demonstrating transfer from letter identification to word identification would not be evidence of the importance of word-related processing in producing context effects. The case for considering transfer to be a consequence of word-based processing, which is required for letter-context effects, is convincing only if transfer in the word-identification task can be shown to be dependent upon processing that is necessary for context effects in the letter-identification task. That is, it would be useful to find a situation in which letter identification fails to yield context effects. Experiments reported by Thompson and Massaro (1973), Johnston and McClelland (1974), and Estes (1975), which used preand postcuing of letter alternatives, afford such a comparison. In these experiments, typical benefits of word context were observed when the letter alternatives were presented after the presentation of a pattern-masked letter string (postcued), as is usually done in the letteridentification task. However, when the letter alternatives were presented above and below the target position before the presentation of a pattern-masked letter string (precued), no effects of word or orthographic context were observed.

One difference between the two cuing orders is that information about the constituent letters and their relative ordering must be maintained in the postcue condition until the letter or position cue is presented (Estes, 1975; Massaro et al., 1979). There is no such demand in the precue condition. Thus, the two orders of cuing make different demands upon temporal buffering of information. In the postcue condition, information about the entire target string must be retained to optimize performance; in the precue condition, information about only a single letter position must be retained. Maintenance of letter and position information for the duration of the visual mask appears to involve coding of the visual display into some form of nonvisual representation. Letter identification using visually confusable letter alternatives (e.g., $\mathrm{M}$ and $\mathrm{N}$ ) is impaired relative to letter identification using featurally distinct alternatives (e.g., M and P) in the precue condition; there is no similar effect in the postcue condition (Thompson \& Massaro, 1973). In sum, the experimental manipulation of pre- and postcuing appears to elicit different encoding operations. Precuing allows encoding operations to focus upon a specific location within the target string, whereas postcuing requires encoding of the target string as a whole. As was succinctly put by Johnston and McClelland (1974), "for the whole to facilitate perception of a part, the subject must attend to the whole"' (p. 1193).

The general plan of the experiment was to measure transfer in the word-identification task following different processing manipulations in a study phase. Transfer was measured by comparing the probability of word identification for a set of studied words (words presented in the study phase) with a set of nonstudied words (words not previously presented in the experiment). The study phase consisted of a letter-identification task, with words and pseudowords serving as the target strings. Processing was manipulated between subjects, with one group receiving a precued letter-identification task and the other group a postcued letter-identification task. The test phase consisted of a word-identification test. It was predicted that words presented in the precued displays would not be processed as words during the letter-identification task and would not facilitate word identification, whereas words presented in the postcued displays would be processed as words and would facilitate word identification.

Word context effects in the letter-identification task were estimated using a procedure described by Estes (1975, Experiment 1). All word and pseudoword target strings were presented in two different types of displays. In the first, a word was presented and the letter alternatives formed a word or pseudoword (Word condition). In the second, a pseudoword was presented and the letter alternatives formed a pseudoword or word (Pseudoword condition). Selection of the target letter in the Word condition indicated correct perception of a word, and selection of the alternative letter indicated the incorrect perception of a pseudoword. In the Pseudoword condition, the relations were reversed; selection of the target letter indicated the correct perception of a pseudoword, and selection of the alternative letter indicated the incorrect perception of a word. This design yielded a joint measure of word superiority effects and response strategies. Letter-identification accuracy should be higher in the Word condition relative to the Pseudoword condition if there is a benefit of word context in perceptual processing, or if there is an effect of lexical constraint at the level of response strategies. In accordance with the predictions outlined above, we expected that there would be no difference between Word and Pseudoword conditions in the precue study condition, but an advantage of Word over Pseudoword in the postcue study condition. We also predicted that words studied in the postcue condition would show an advantage over new words in the wordidentification task, whereas words studied in the precue 
condition and new words would show similar levels in word identification.

A third condition, a lexical decision task, was included in the experiment to provide an estimate of the degree of transfer when the study task formally required word processing. The lexical decision task employed the same stimulus strings and parameters of physical presentation that were used in letter identification. Thus, any difference in transfer between the letter-identification tasks and the lexical decision task would reflect different degrees of word access in the different study tasks.

\section{METHOD}

\section{Subjects}

Fifty-four students enrolled in an introductory psychology course at McMaster University volunteered as subjects. They were assigned randomly to one of three study conditions: precued letter identification, postcued letter identification, and lexical decision, with 18 subjects in each group.

\section{Materials}

One hundred and twenty words were selected from the ThorndikeLorge (1944) wordbook; 60 were low-frequency words (1-13 occurrences per million, with an average frequency of 4.25 ) and 60 were high-frequency words (A and AA). Half of the words of each frequency were five-letter words and half were six-letter words. A complementary set of 120 pseudowords was constructed by randomly replacing a single letter in each word, with the constraint that each letter position be replaced equally often for both highand low-frequency words. Both consonants and vowels were replaced. Any word created by this process was thrown away, and the process was repeated until a pseudoword was found. The 120 word-pseudoword pairs were divided into three subsets of 40 pairs, with 20 high- and 20 low-frequency words and their derived pseudowords in each subset.

\section{Design}

The experiment consisted of two phases: (1) a study phase manipulating the orientation task between subjects (pre- or postcued letter identification, or lexical decision), and (2) a common test phase using the word-identification task. In the study phase, each subject was presented with $\mathbf{4 0}$ words (Word condition) from one subset and 40 pseudowords (Pseudoword condition) from one of the remaining subsets. In the test phase, the 120 words from all three subsets were presented tachistoscopically. Thus, there were three test conditions for each group: (1) Old words-words presented in the Word condition, (2) Old pseudowords-- base words corresponding to pseudowords presented in the Pseudoword condition, and (3) New words-words not previously seen during the experiment, and used as a control for estimating transfer in word identification. For transfer to be observed, the probability of identification for Old words would need to exceed the probability of identification for New words. The assignment of subsets to study and test conditions within each group was rotated across subjects, such that the items from each subset served equally often in the three test conditions.

The presentation of stimuli and the scoring of responses were controlled by an Apple computer with a 14-in. Zenith monitor. The use of a CRT monitor limited display durations to multiples of $1 / 60 \mathrm{sec}$, or $16.7 \mathrm{msec}$. The subjects responded in the first phase by pressing one of two designated keys. In the second phase, the subjects were required to name, if possible, the word flashed on the screen.
The stimuli, composed of $7 \times 8$ dot matrix letters, were shown in lowercase, with letters separated by a single space character Lowercase stimuli were used because previous research (Jacoby \& Hayman, 1987) had shown that transfer in the word-identification task appeared to be greater for lowercase stimuli than for uppercase stimuli. The spacing of letters was based on a pilot experiment and served to increase performance in the letter-identification task, perhaps by allowing subjects to focus their attention in the right place. Johnston and McClelland (1974) used a similar spacing arrangement. At a $70-\mathrm{cm}$ viewing distance, the target strings subtended approximately $.5^{\circ}$ of visual angle vertically and $4.5^{\circ}$ or $5.5^{\circ}$ of visual angle horizontally, for five- and six-letter words, respectively. Selection of the display duration used in the first phase was also determined during the pilot experiment. Because we wished to exclude possible differences in transfer due to display duration in the study task, the display duration was constant for the three study conditions. The display duration chosen from the pilot experiment $(83 \mathrm{msec})$ appeared to give acceptable rates of performance for the three tasks.

\section{Procedure}

The procedure and display changed only slightly across the three subject groups. The major difference between subject groups was produced by the manipulation of instructions.

Study phase. The procedure for the precue group is displayed in Table 1 . On each trial, the stimulus position was indicated by a display location approximately in the center of the screen (line A). The subject initiated a trial by pressing the return key to display information about letter alternatives and letter position before the target display. For example, in line B the letter alternatives ( $\mathrm{g}$ and b) are located in the fourth position of a six-letter target. The subjects were told that one of the two letters shown in the display would be flashed in that position in a string of letters. The tachistoscopic sequence (lines $D$ and $E$ ) began 700 msec after the second keypress. The target string (word or pseudoword) was presented for about $83 \mathrm{msec}(5 \times 16.7 \mathrm{msec})$ and was terminated by a 200 -msec pattern mask. The subjects ended each trial with two responses, one to select a letter alternative and the same response again to confirm their choice (lines $F$ and $G$ ). The subjects could change the selection if they did so before the second keypress. The subjects only rarely made use of this feature, and it is unlikely that the exclusion of this opportunity to change their selection would have significantly affected accuracy. The results reported are based on the last response.

The postcue group was presented with the same procedure and instructions as the precue group, with the exception that the letter alternatives (lines F and G) were presented only after the target display. The instructions were modified appropriately.

Subjects in the lexical decision group were presented with the same display sequence used for the letter-cued groups, but all letter alternatives were removed from the display. That is, the same display sequence shown in Table 1 was followed, with the letter alternatives from frames $B, F$, and $G$ removed. The subjects were told that after the second keypress, a word or a pseudoword would be flashed, and that they were to indicate their choice by pressing one of two keys twice. The "up" key indicated a word; the "down" key indicated a pseudoword

An experimental session began with a practice list of four words and four pseudowords presented in random order. The practice trials served to introduce the experimental procedure and to familiarize the subjects with the display. The first of these eight stimuli was presented for a duration of about $183 \mathrm{msec}$, which allowed all subjects to easily perceive the target string. The presentation duration of the next six practice stimuli was decreased by $16.7 \mathrm{msec}$. The last practice stimulus appeared for the same duration as that used with the study presentations. 
Table 1

Outline of Study Phase: Precued, Letter Detection

\begin{tabular}{|c|c|c|c|c|c|}
\hline Line & & Display & & Duration & Response \\
\hline A & ++ & & ++ & & $<$ Press RETURN > \\
\hline B & -- & $\begin{array}{c}\mathrm{b} \\
\# \# \# \# \# \\
\mathrm{~g}\end{array}$ & -- & & $<$ Press RETURN > \\
\hline C & $-\infty$ & & -- & $700 \mathrm{msec}$ & \\
\hline D & -- & finger & -- & $83 \mathrm{msec}$ & \\
\hline $\mathbf{E}$ & -- & $\& \& \& \& \& \&$ & -- & $200 \mathrm{msec}$ & \\
\hline$F$ & -- & $\begin{array}{l}\mathrm{b} \\
\mathrm{g}\end{array}$ & $--?$ & & $<$ 'Up' or 'Down' > \\
\hline G & -- & $\begin{array}{l}\mathrm{b} \\
\mathrm{g}\end{array}$ & - & & $<$ 'Down' > \\
\hline
\end{tabular}

Test phase. The test of perceptual word identification was identical for all three study groups. The display sequence is shown in Table 2. Subjects were informed that words would be flashed on the screen and that they were to quickly pronounce each word detected, guessing if necessary. Each trial began with the message "Press when ready" at the bottom of the screen. When the subjects indicated that they were ready, the original message was replaced by a set of fixation bars $\left(-C_{-}-\right.$) that appeared for $500 \mathrm{msec}$ surrounding the location where the test word was presented. The test word was presented for about $33 \mathrm{msec}$ $(2 \times 16.7 \mathrm{msec})$, and was terminated by a 200 -msec presentation of a mask ( $-\& \& \& \& \& \& \& \&-)$ presented in the same location as the test word. For each subject, the word-identification task began with 15 practice trials. The first practice word was presented for $133 \mathrm{msec}$. The presentation duration for the following practice words was decreased by $16.7 \mathrm{msec}$ every second word, until the test rate of $33 \mathrm{msec}$ was reached. The presentation duration in the last four practice trials was the same as that used in the test phase.

\section{RESULTS AND DISCUSSION}

The significance level was set at $p<.05$ for all comparisons.

\section{Study Phase}

The mean proportions of correct responses in letter identification for the pre- and postcue groups and for word and pseudoword stimuli are shown in Table 3. As can be seen, letter identification in words was superior to letter identification in pseudowords only in the postcue group.
This was confirmed in a $2 \times 2 \times 2$ ANOVA (two orders of cuing, two types of stimulus, and two levels of word frequency). There were significant main effects of cuing $\left[F(1,34)=64.8, M S_{\mathrm{e}}=.0069\right]$, and type of stimulus $\left[F(1,34)=128.1, M S_{\mathrm{e}}=.0037\right]$. However, since the interaction between cuing (pre- or postcue) and stimulus (word or pseudoword) was also significant $[F(1,34)=$ $98.9, M S_{\mathrm{e}}=.0037$, the main effects will not be analyzed further. The source of the interaction is clear. Accuracy was lower in the postcued pseudoword condition $(M=.751)$ than in the postcued word $(M=.967)$, the precued word $(M=.978)$, and the precued pseudoword $(M=.964)$ conditions. Accuracy in the latter three conditions approached ceiling. Post hoc comparisons using Scheffé's test $(d f=3,34)$ with a critical difference of .060 confirmed this interpretation.

Neither the main effect of word frequency nor any interactions involving word frequency approached significance ( $F<1$ for all comparisons).

In summary, the study manipulation of pre- and postcued letter alternatives produced the predicted results. In the precue conditions there were no significant effects of letter context, whereas in the postcue conditions there was the expected superiority of letter identification in word stimuli over pseudoword stimuli.

The mean proportions of correct responses for the lexical decision task are also shown in Table 3. A $2 \times 2$ ANOVA (two types of items and two levels of word fre-

Table 2

Outline of Test Phase: Word Identification

\begin{tabular}{cccccc}
\hline Line & & Display & & Duration & Response \\
\hline A & ++ & & ++ & & < Press RETURN > \\
B & -- & & -- & $500 \mathrm{msec}$ & \\
C & -- & finger & -- & $33 \mathrm{msec}$ & \\
D & -- & \&\&\&\&\&\&\&\& & -- & $200 \mathrm{msec}$ & \\
E & -- & & -- & & < Name word > \\
\hline
\end{tabular}


Table 3

Mean Proportion of Correct Responses for Pre- and Postcued Letter Identification and Lexical Decision in the Study Phase

\begin{tabular}{|c|c|c|c|c|}
\hline \multirow[b]{3}{*}{ Study Task } & \multicolumn{4}{|c|}{ Word Frequency } \\
\hline & \multicolumn{2}{|c|}{ High } & \multicolumn{2}{|c|}{ Low } \\
\hline & $M$ & $S D$ & $M$ & $S D$ \\
\hline \multicolumn{5}{|c|}{ Study Stimulus: Word } \\
\hline \multicolumn{5}{|c|}{ Letter Alternatives } \\
\hline Precued & .972 & .031 & .983 & .030 \\
\hline Postcued & .969 & .039 & .964 & .038 \\
\hline Lexical Decision & .903 & .104 & .717 & .161 \\
\hline \multicolumn{5}{|c|}{ Study Stimulus: Pseudoword } \\
\hline \multicolumn{5}{|c|}{ Letter Alternatives } \\
\hline Precued & .956 & .059 & .972 & .052 \\
\hline Postcued & .747 & .105 & .755 & .100 \\
\hline Lexical Decision & .736 & .150 & .794 & .128 \\
\hline
\end{tabular}

quency) revealed a significant main effect of word frequency $\left[F(1,17)=5.17, M S_{\mathrm{e}}=.0014\right]$, and a significant interaction between stimulus type (word or pseudoword) and word frequency (high or low) $[F(1,17)$ $\left.=27.52, M S_{\mathrm{e}}=.0098\right]$. In a post hoc test using Scheffe's test $(d f=1,17)$ with a critical difference of .102 , it was found that lexical decisions were more accurate for high-frequency words $(M=.903)$ than for low-frequency words $(M=.717)$. There were no significant differences in accuracy for pseudowords derived from high- and lowfrequency words $(M=.736$ and .794 , respectively).

\section{Test Phase}

Old words versus New words. The mean proportions of correct responses in word identification are presented in Table 4. The results are clear-cut: prior presentation of a word in both the postcue and lexical decision study conditions facilitated later identification, whereas prior presentation in the precue study condition did not. This

Table 4

Mean Proportion of Correct Responses in the Word-Identification Test

\begin{tabular}{lllll}
\hline & \multicolumn{3}{c}{ Word Frequency } \\
\cline { 2 - 3 } Study Task & $M$ & $S D$ & $M$ & $S D$ \\
\hline
\end{tabular}

Test Condition: Study-Word

Letter Alternatives

$\begin{array}{lllll}\text { Precued } & .744 & .172 & .486 & .198 \\ \text { Postcued } & .858 & .127 & .681 & .178 \\ \text { Lexical Decision } & .867 & .139 & .647 & .203\end{array}$

$\begin{array}{lllll}\text { Lexical Decision } & 867 & .139 & .647 & .203\end{array}$

Letter Alternatives

$\begin{array}{lllll}\text { Precued } & .731 & .154 & .494 & .218 \\ \text { Postcued } & .775 & .130 & .558 & .195 \\ \text { Lexical Decision } & .750 & .205 & .547 & .191\end{array}$

Test Condition: Study-Pseudoword

Letter Alternatives

\begin{tabular}{lllll} 
Precued & .753 & .129 & .467 & .228 \\
Postcued & .792 & .118 & .569 & .193 \\
Lexical Decision & .792 & .155 & .625 & .227 \\
\hline
\end{tabular}

interpretation was confirmed in a $3 \times 2 \times 2$ ANOVA [three study tasks, two types of items (Old/New), and two levels of word frequency]. Although the main effect of study task was not significant $\left[F(2,51)=2.41, M S_{e}=.0944\right]$, there was a significant main effect of prior presentation $\left[F(1,51)=32.67, M S_{\mathrm{e}}=.0084\right]$ and a significant interaction between study task and prior presentation $[F(2,51)$ $\left.=7.56, M S_{\mathrm{e}}=.0084\right]$. Fisher's $L S D(.061)$ for planned comparisons revealed a significant effect of a prior presentation (Old $>$ New) in the postcue ( $M=.769$ vs. .667 ) and lexical decision $(M=.757$ vs. .649$)$ conditions, but not in the precue ( $M=.615$ vs. .612$)$ condition.

There was a significant effect of word frequency $\left[F(1,51)=174.76, M S_{c}=.0147\right]$. As expected, highfrequency words were identified more accurately than low-frequency words. All other comparisons involving word frequency failed to approach significance (all $F$ s $<1$ ).

In summary, presentation of a word in the precued-letter-identification task did not produce any facilitation for subsequent word processing. In contrast, presentation of a word in the postcued-letter-identification task produced strong facilitation in subsequent identification of these words. Indeed, the transfer observed for words presented in the postcued-letter-identification task, in which the subjects' task was ostensibly letter identification, was not significantly different from the transfer observed for words presented in the lexical decision task, in which subjects were required to attend to words. Since the physical duration of the displays was identical in all three groups, it can be concluded that variations in processing must necessarily account for this difference in transfer. Inasmuch as subjects in the precued-letteridentification condition exhibited no effects of word context in the study manipulation or word transfer in a following test, whereas subjects in the postcued-letteridentification condition revealed both effects of word context during study and transfer in a following test, it can be concluded that the two tasks differ in their use of wordbased processing.

Words presented as pseudowords at study versus New words. These data are summarized in the bottom six rows of Table 4 . In a $3 \times 2 \times 2$ ANOVA [three study tasks, two types of items (Old/New), and two levels of word frequency], the main effect of the study task was not significant $\left[F(2,51)=1.04, M S_{\mathrm{e}}=.0972\right]$.

As expected, the difference in identification accuracy attributable to word frequency was highly significant $\left[F(1,51)=173.9, M S_{\mathrm{e}}=.0153\right]$, with high-frequency words identified more accurately than low-frequency words. There were no significant interactions involving frequency $\left[F(2,51)=1.72, M S_{\mathrm{e}}=.0152\right]$ for frequency $\times$ study task, and $F \mathrm{~s}<1$ for all other comparisons.

Surprisingly, there was a small, but significant, main effect of prior presentation $[F(1,51)=4.10$, $\left.M S_{\mathrm{e}}=.0073\right]$, with words presented as pseudowords identified more accurately than New words $(M=.666$ and .642 , respectively). The interaction between prior 
presentation and study task approached significance $\left[F(2,51)=2.57, M S_{\mathrm{e}}=.0073, p<.09\right]$; all other interactions with prior presentation produced $F \mathrm{~s}<1$.

Although the interaction between study task and prior presentation in the Pseudoword condition was not statistically significant, there was a numerically smaller effect of prior pseudoword presentation in the letteridentification tasks than in the lexical decision task. The largest facilitation of a prior presentation was observed with low-frequency words in the lexical decision task. If it is assumed that the transfer from a pseudoword presentation to word identification is real, there are two possible interpretations of this transfer. First, transfer could be a result of indirect activation of similar words during pseudoword presentation, with many words being partially activated. Second, the transfer may be a result of direct activation of a word produced as an error, with only this incorrect word being activated by the pseudoword. We view the second interpretation as the more plausible of the two. It also receives some support from an examination of the conditional probabilities of word identification.

When the probability of low-frequency word identification in the lexical decision Pseudoword condition was conditionalized on study response, a clear pattern emerged. When pseudowords were correctly detected at study, there were essentially no differences at test between the probability of identifying base words in the Pseudoword condition $(M=.60)$ and the probability of identifying New words $(M=.55, z=1.8, p>.05$, twotailed). However, when base words appeared as errors to pseudowords at study, there was an increase in the probability of identifying these words $(M=.71)$ compared to the probability of identifying New words $(M=.55$, $z=6.0, p<.001$, two-tailed). There was a similar but much weaker trend for high-frequency words. Thus, the transfer observed in the Pseudoword condition appeared to be restricted to base words produced as errors during the study phase.

A possible problem in conditionalizing word identification on study response is some form of item selection. That is, if some items are more easily perceived than others, then those items are more likely to be a source of errors in the study phase and to be correctly perceived in the test phase. This does not appear to be a serious problem in the present case. A necessary consequence of item selection is that words that are not produced as errors to pseudowords in the study phase should also be poorly perceived in the test phase. All other things being equal, these words would be expected to be less well perceived than New words, which represent an average of poorly and well-perceived words. Since, in the present case, words not produced as errors to pseudowords in the study phase are as likely to be identified as New words, item selection can be ruled out as the sole cause of the differences observed between the conditional probabilities in the Pseudoword condition.

In conclusion, a plausible interpretation of the small, but significant, effect of a prior presentation in the
Pseudoword condition is to assume that this facilitation represents transfer in processing from the words perceived erroneously during a pseudoword presentation.

\section{GENERAL DISCUSSION}

The present results offer clear support for the hypothesis that performance in the letter-identification task can be used to predict transfer in a word-identification task. The presentation of words in a letter-identification task that is sensitive to effects of word context will result in the facilitated perception of those words in a following wordidentification task, whereas the presentation of words in a letter-identification task that does not show effects of word context has no observable consequence in the wordidentification task. Thus, the results provide converging evidence for the assumption that the processing responsible for word context effects in the letter-identification task is associated with processing specific to individual words. That is, the hypothesis of mediation by wordassociated processing in letter identification gains predictive as well as descriptive power. These results are relevant to explanations of the letter-identification task offered by McClelland and Rumelhart (1981) and Paap et al. (1982), which hypothesize an active involvement of wordspecific constraints in letter identification.

The near-ceiling performance in the current precued-letter-identification task may be perceived as limiting the generality of the current results. This could be true, however, only if it were hypothesized that in measuring context effects in the precued condition, the failure to find a context effect in the precued condition was a result of low sensitivity, attributable to asymptotic performance levels. There are two responses to arguments of this nature. First, no letter context effects were observed in the experiments by Thompson and Massaro (1973) and Johnston and McClelland (1974), where performance was below ceiling levels and sensitivity was not a problem. Second, because sensitivity was not a major problem in word identification, the findings of transfer in the postcue condition and no transfer in the precue condition provide converging evidence that differences in word processing occurred for the two tasks. The near asymptotic performance in the precue study condition, with the associated low sensitivity of measures for context effects, would have been a more serious problem if transfer had been observed in both pre- and postcue conditions.

\section{Implications for Models of Letter and Word Perception}

Although the present experiment was not designed to test the particular assumptions of the McClelland and Rumelhart (1981) or Paap et al. (1982) models of context effects in the letter-identification task, the current results do have certain implications for those models.

In the activation-verification model proposed by Paap et al. (1982), words are processed sequentially over two 
discrete stages. Preliminary word processing and letter identification are mediated by the first stage. Word effects, such as word frequency and repetition effects, are localized in the second or verification stage. Furthermore, because brief, pattern-masked displays, such as those used in the letter-identification task, by definition disrupt the verification process (Paap et al., 1982, p. 574), such factors as word frequency and repetition priming that influence word identification cannot affect letter identification.

However, if the effect of repetition is mediated by changes in the verification stage, and the tachistoscopic display used in the study task precludes processing in the verification stage, then it is difficult to see how the activation-verification model can accommodate the word transfer observed for the postcue and lexical decision conditions. Moreover, responses in the lexical decision task during study clearly contradict the assumption that the presence and/or absence of word-frequency effects is controlled by brief, pattern-masked displays. The stimuli in all three study conditions were presented under identical physical constraints, but word frequency was an important factor only when instructions required lexical decisions. Dobbs, Friedman, and Lloyd (1985) also found that lexical decisions for frequent words were more accurate than lexical decisions for rare words with tachistoscopically presented and pattern-masked displays. In conclusion, the two-stage assumptions employed in the activation-verification model to explain the absence of word effects in letter identification cannot, without modification, account for the present results.

The interactive activation model proposed by McClelland and Rumelhart (1981) handles the different effects of word frequency on letter and word identification with the assumptions that (1) letter-identification tasks are performed by decisions made at the letter level, with feedback from active word detectors constraining letter activation, and (2) word-identification tasks are performed by decisions made at the word level. Consequently, the present observation that conditions leading to context effects in letter identification also lead to transfer, while conditions failing to elicit context effects in letter identification also fail to yield significant transfer, is consistent with the interactive activation model and, indeed, contributes to its plausibility.

\section{Ilusory Perception}

A common report in experiments dealing with tachistoscopic letter identification (Adams, 1979; Estes, 1975; McClelland, 1976) has been that subjects often claim to have actually seen a word during the masked display of a pseudoword. That is, there is an illusory perception of a word. The current observation of transfer in the Pseudoword condition may reflect a similar phenomenon and, if so, offers additional information about the nature of this illusory perception. As will be remembered, prior presentation of pseudowords had an unexpected positive benefit for the subsequent identification of the base words from which the pseudowords were derived. Furthermore, when accuracy in word identification was conditionalized upon a correct pseudoword or an incorrect word response during the study task, there was a general tendency for the words incorrectly produced at study to exhibit transfer in the word-identification task, while correct identification of the derived pseudoword during study left the probability of identification of the base word unchanged, relative to a set of new words. If words produced as errors to similar pseudowords at study represent illusory perceptions of the type described by Estes (1975), McClelland (1976), and Adams (1979), then the fact that these illusory perceptions also appear to produce transfer in subsequent word identification implies that the illusion occurs before or at the level of word perception. That is, to the extent that transfer in the word-identification task reflects processing specific to a visual occurrence of a word (Jacoby \& Hayman, 1987), transfer from the illusory perception of a word requires processing that is functionally equivalent to that of a correct visual perception of a word.

\section{Boundary Conditions for Automatic Processing}

A popular assumption with regard to word encoding has been that words are automatically encoded (Morton, 1979; Posner \& Snyder, 1975; Tweedy, Lapinski, \& Schvaneveldt, 1977). Automatic, here, means that words are encoded independently of the resources controlled by attention (Posner \& Snyder, 1975) and/or without regard to a subject's processing intentions (Morton, 1979; Tweedy et al., 1977). The general automaticity hypothesis has been modified by Kahneman and Treisman (1986), who argue for degrees of automaticity because research has revealed situational factors that affect the probability of word encoding. The present results are not easily accommodated within a strong automaticity perspective. Word transfer, and by inference prior word encoding, varied markedly between pre- and postcue conditions in the present experiment. Since words were presented under identical physical and temporal conditions but with different instructions, the differences observed in word encoding must reflect differences in attention. Although it may be possible to characterize word encoding in the precue condition as weakly automatic, it is perhaps more useful to treat processing in the precue condition as falling outside the domain of automatic word encoding. That is, there may be boundary conditions within which it is useful to treat word encoding as automatic. However, outside these conditions, the presence or absence of word encoding must be specified in terms of attentional demands. A complete account of automatic word encoding must necessarily specify the nature of these boundary conditions.

Clearly, the display alone is not sufficient to limit word processing. Word encoding occurred when the task was postcued letter identification or lexical decision, using the same temporally and physically limited displays. Furthermore, word encoding in the standard letter-identification 
task, using postcued responses, appears to be automatic in character (Carr, Davidson, \& Hawkins, 1978). The results from our experiment join those from earlier experiments (e.g. Jacoby, 1983a; Whittlesea \& Cantwell, 1987) in demonstrating the importance of the details of the study processing of a word for its later perceptual identification. Consistent with an episodic view of perception (Jacoby \& Brooks, 1984; Whittlesea, 1987), effects on perceptual identification reflect variations on the processing of an item during its prior presentation.

There is some evidence that focusing attention on letters at a particular position in a word string excludes word encoding when the display presentation is neither tachistoscopic nor masked (Smith, 1979). In Smith's task, subjects were required to locate a probe letter in a simultaneously presented letter string. When successive trials used the same word and a single probe letter, the subjects were faster in locating the probe letter in the repeated word; when successive trials used different probe letters, there was no speed advantage for repeated words. Smith interpreted these results as indicating word encoding when there was a speed advantage in the second presentation and letter-by-letter processing when there was no advantage in the second presentation. It is not clear, however, whether Smith's manipulation prevents automatic word encoding or simply excludes facilitation from repeated words in simultaneous letter identification. In the latter case, word encoding could still occur during the task but simply fail to affect letter performance. A test of word transfer could distinguish between these alternatives. If word encoding is affected by the task manipulation, there should be word-based transfer when there is a word advantage and no transfer when there is no word advantage. Although Smith (1979) did not use a transfer test of prior word processing, such a result would provide additional evidence for the dependence of word encoding on task constraints.

\section{Conclusion}

The primary purpose of the present research was to explore the possibility of using transfer to the wordidentification task as a test of prior word processing in such paradigms as the letter-identification task. Explanations of context effects in letter identification, such as those of McClelland and Rumelhart (1981) and Rumelhart and McClelland (1982), appeal to constraints derived from the concurrent processing of individual words, yet provide no direct or independent measure of word processing. We conclude that transfer, such as that observed in repetition experiments (e.g., Jacoby, 1983b; Kolers, 1979; Morton, 1979; Scarborough, Cortese, \& Scarborough, 1977; Tulving, Schacter, \& Stark, 1982), can serve as a useful measure of the extent and/or occurrence of wordrelated processing that occurs in the letter-identification task, and in other tasks where the primary requirements of the task define, and thus restrict, the measures of processing available during the task. Such research pro- vides not only converging evidence about the presence and/or absence of processes that can only be inferred, but also a link between the different research paradigms used in examining skilled performance.

\section{REFERENCES}

Adams, M. J. (1979). Models of word recognition. Cognitive Psychology, 11, 133-176.

Carr, T. H., Davidson, B. J., \& Hawkins, H. L. (1978). Perceptual flexibility in word recognition: Strategies affect orthographic computation but not lexical access. Journal of Experimental Psychology: Human Perception \& Performance, 4, 674-690.

Dobrs, A. R., Friedman, A., \& Lloyd, J. (1985). Frequency effects in lexical decisions: A test of the verification model. Journal of $E x$ perimental Psychology: Human Perception \& Performance, 11, 81-92.

ESTES, W. K. (1975). The locus of inferential and perceptual processes in letter identification. Joumal of Experimental Psychology: General, 104, 122-145.

JACOBY, L. L. (1983a). Perceptual enhancement: Persistent effects of an experience. Journal of Experimental Psychology: Learning, Memory, \& Cognition, 9, 21-38.

$J_{A C O B Y}$ L. L. (1983b). Remembering the data: Analyzing interactive processes in reading. Joumal of Verbal Learming \& Verbal Behavior, 22, 485-508.

JACOBY, L. L., \& Brooks, L. R. (1984). Nonanalytic cognition: Memory, perception, and concept formation. In G. H. Bower (Ed.), The psychology of learning and motivation (Vol. 18, pp. 1-47). New York: Academic Press.

JACOBY, L. L., DALLAS, M. (1981). On the relationship between autobiographical memory and perceptual learning. Joumal of Experimental Psychology: General, 110, 306-340.

JaCOBY, L. L., \& Hayman, C. A. G. (1987). Specific visual transfer in word identification. Journal of Experimental Psychology: Leaming, Memory, \& Cognition, 13, 456-463.

Johnston, J. C., \& MCClelland, J. L. (1974). Perception of letters in words: Seek not and ye shall find. Science, 184, 1192-1194.

Kahneman, D., \& Treisman, A. (1986). Changing views of attention and automaticity. In R. Parasuraman, R. Davies, \& J. Beaty (Eds.), Varieties of attention (pp. 29-62). New York: Academic Press.

Kolers, P. A. (1979). A pattern-analyzing basis of recognition. In L. S. Cermak \& F. I. M. Craik (Eds.), Levels of processing in human memory (pp. 363-384). Hillsdale, NJ: Erlbaum.

Kolers, P. A., \& Roediger, H. L. III. (1984). Procedures of mind. Journal of Verbal Learning \& Verbal Behavior, 23, 425-449.

Massaro, D. W., Venezky, R. L., \& TAYlor, G. A. (1979). Orthographic regularity, positional frequency, and visual processing of letter strings. Journal of Experimental Psychology: General, 108, 107-124.

MCClelland, J. L. (1976). Preliminary letter identification in the perception of words and nonwords. Journal of Experimental Psychology: Human Perception \& Performance, 2, 80-91.

McClelland, J. L., \& Rumelhart, J. L. (1981). An interactive activation model of context effects in letter perception: Part 1 . An account of basic findings. Psychological Review, 88, 375-407.

MoRTON, J. (1979). Facilitation in word recognition: Experiments causing change in the logogen models. In P. A. Kolers, M. E. Wrolstad, \& H. Bouma (Eds.), Processing of visible language (Vol. 1, pp. 259268). New York: Plenum.

MURRell, G. A., \& MoRToN, J. (1974). Word recognition and morphemic structure. Joumal of Experimental Psychology, 102, 963-968.

PaAP, K. R., Newsome, S. L., McDonald, J. E., \& Schvaneveldt, R. W. (1982), An activation-verification model for letter and word recognition: The word-superiority effect. Psychological Review, 89, 573-594.

Posner, M. I., \& SNYDER, C. R. R. (1975). Attention and cognitive control. In R. L. Solso (Ed.), Information processing and cognition: The Loyola symposium (pp. 55-86). Hillsdale, NJ: Erlbaum.

Reicher, G. M. (1969). Perceptual recognition as a function of the 
meaningfulness of stimulus material. Journal of Experimental Psychology, 81, 275-280.

Rumelhart, D. E., \& MCClelland, J. L. (1982). An interactive activation model of context effects in letter perception: Part 2. The contextual enhancement effect and some tests and extensions of the model. Psychological Review, 89, 60-94.

Scarborough, D. L., Cortese, C., \& Scarborough, H. S. (1977). Frequency and repetition effects in lexical memory. Journal of Experimental Psychology: Human Perception \& Performance, 3, 1-17. SмIтн, M. C. (1979). Contextual facilitation in a letter search task depends on how the prime is processed. Journal of Experimental Psychology: Human Perception \& Performance, 5, 239-251.

Thompson, M. C., \& Massaro, D. W. (1973). Visual information and redundancy in reading. Journal of Experimental Psychology, 98, 49-54.

THORNDIKE, E. L., LoRGE, I. (1944). The teacher's word book of 30,000 words. New York: Columbia University Press.

Tulving, E., Schacter, D. L., Stark, H. A. (1982). Priming effects in word-fragment completion are independent of recognition memory. Journal of Experimental Psychology: Learning, Memory, \& Cognition, 8, 336-342.

Tweedr, J. R., Lapinski, R. H., \& SchVaneveldt, R. W. (1977). Semantic-context effects on word recognition: Influences of varying the proportion of items presented in an appropriate context. Memory \& Cognition, 5, 84-89.

Wheeler, D. D. (1970). Processes in word recognition. Cognitive Psychology, 1, 59-85.

Whittlesea, B. W. A. (1987). Preservation of specific experiences in the representation of general knowledge. Journal of Experimental Psychology: Learning, Memory, \& Cognition, 13, 3-17.

Whittlesea, B. W. A., \& Cantwel.t, A. L. (1987). Enduring influence of the purpose of experiences: Encoding-retrieval interactions in word and pseudoword perception. Memory \& Cognition, 15, 465-472.

(Manuscript received July 18, 1986; revision accepted for publication August 1, 1988.) 